\section{Alexandre Rodrigues Ferreira e a capitania de Mato Grosso: imagens do interior}

\section{Alexandre Rodrigues Ferreira and} capitania de Mato Grosso: images of the Brazilian inland
COSTA, M. de F.: 'Alexandre Rodrigues Ferreira e a capitania de Mato Grosso: imagens do interior'.

História, Ciências, Saúde-Manguinhos, vol. VIII (suplemento), 993-1014, 2001

No momento crucial das demarcações de limites entre as duas Américas ibéricas, a Viagem Filosófica de Alexandre Rodrigues Ferreira reconhecia parte das terras brasileiras. Entre 1789 e 1791, sua expedição esteve na capitania de Mato Grosso, penetrando até os confins do Pantanal. No estudo dos textos e traços produzidos nesta viagem, emergem algumas das primeiras imagens do Brasil interior.

PALAVRAS-CHAVE: Alexandre Rodrigues Ferreira, século XVIII, viagens, coleções científicas, fronteiras, história natural.

COSTA, M. de F.: 'Alexandre Rodrigues Ferreira and capitania de Mato Grosso: images of the Brazilian inland'.

História, Ciências, Saúde-Manguinhos, vol. VIII (supplement), 993-1014, 2001

At the crucial moment when frontier boundaries between the two Iberian Americas were being established, Alexandre Rodrigues Ferreira carried out his Philosophical Journey into Brazilian lands. From 1789 to 1791, his expedition crossed the capitania de Mato Grosso until the far lowlands of Pantanal. From the analysis of the texts and other records produced during the trip, some of the first images of Brazilian inland come to light.

KEYWORDS: Alexandre Rodrigues Ferreira, $18^{\text {th }}$ century, scientific journeys, scientific collections, frontiers, natural history.
Maria de Fátima Costa

Professora-pesquisadora do Departamento de História

Universidade Federal de Mato Grosso (UFMT) Caixa Postal 3505

78070-970 Cuiabá — MT Brasil

fadiener@homeshopping.com.br 


\section{Introdução}

Setecentos caracterizou-se por grandes avanços nas ciências, que, impulsionadas pelos novos conhecimentos e métodos, lançavam luzes sobre as diversas áreas do saber. Parte significativa deste avanço foi empregada nas grandes viagens realizadas por expedições científicas como as capitaneadas por Louis-Antoine de Bouganville (1766-69), James Cook (1768-77) e Jean-François de La Pérouse (1785-88), que ampliaram o conhecimento sobre a geografia dos continentes e trouxeram a público várias centenas de novas informações sobre os reinos mineral, vegetal e animal. Eram as grandes viagens marítimas que circunavegavam, tocando as faixas litorâneas das áreas ainda quase desconhecidas: mitos geográficos iam sendo desfeitos, pigmeus e gigantes tiveram seus territórios reduzidos, povos com outras culturas foram encontrados e o desenho do planeta se aproximava de suas reais dimensões.

Estas expedições, entretanto, pouco conhecimento podiam oferecer sobre as terras interiores. No continente americano, exceções a estas são certamente a expedição franco-espanhola ao reino de Quito, entre 1735 e 1745, e as expedições demarcadoras de limites que, por força dos tratados assinados entre Portugal e Espanha, passaram a percorrer a raia fronteiriça destas coroas ibéricas na América, descortinando alguns aspectos do interior sul-americano.

Alexander von Humboldt, na introdução a Viagens às regiões equinociais, publicada em Paris em 1816, estabelece uma comparação entre viagens marítimas e viagens ao interior, deixando claro que só é possível conhecer um lugar quando se consegue penetrar no seu espaço continental. Conforme apregoa, não é nas costas que se reconhece o rumo das cadeias de montanhas nem os povos que as habitam, nem tampouco suas produções animais e vegetais, muito menos a composição dos solos. De fato, um dos aspectos que freqüentemente se valora na viagem humboldtiana é o fato de este prussiano ter palmilhado grande porção do território interior americano, demonstrando que o conhecimento de um lugar só ocorre quando se adentra os seus recônditos, quando se interioriza.

Mas devemos lembrar que sete anos antes de Humboldt chegar à América, já em 1792 o luso-brasileiro Alexandre Rodrigues Ferreira concluía a expedição pelo interior sul-americano. Foram quase dez os anos que este ilustrado naturalista passou entre águas e terras da Amazônia e do Pantanal brasileiros. Nesse tempo, atravessou territórios de diversos povos e nações indígenas e trouxe, impulsionado pelas luzes da ciência setecentista, um imensurável cabedal de conhecimentos para as diversas áreas do saber.

Sua empresa em muito difere da que empreenderia o barão de Humboldt, que viajou a suas expensas e seguiu os próprios roteiros e diretrizes. A expedição de Rodrigues Ferreira inscreve-se na modalidade 
das Viagens Filosóficas — um tipo de expedição científica, ideada por Domingos Vandelli, inteiramente organizada, dirigida e financiada pelo Estado lusitano já no período pós-pombalino, com a finalidade de explorar as riquezas no interior do território colonial, principalmente do Brasil. Vandelli, o realizador das reformas na Universidade de Coimbra, propôs este tipo de expedição em 1779.

Logo depois, foram enviadas três Viagens Filosóficas aos territórios coloniais: uma a Moçambique (1783-93), chefiada por Manoel Galvão da Silva; outra a Angola (1783-1808), liderada por José da Silva; e essa ao Brasil, encabeçada por Alexandre Rodrigues Ferreira.

Nascido na cidade da Bahia e educado em Portugal, Ferreira tem uma biografia bastante estudada e conhecida (Sá, 1817; Correa Filho, 1939; Goeldi, 1982; Fontes, s. d.). Ao assumir a chefia da expedição científica que viajou pelo interior do Brasil entre 1783 e 1792, era um jovem de 27 anos, recém-egresso da Universidade de Coimbra, na qual havia se doutorado em filosofia natural, em 1779. Discípulo brilhante dos mestres ilustrados que acudiram às terras lusitanas durante a reforma universitária imposta pelo marquês de Pombal, Ferreira veio para a colônia com o objetivo de "proceder, nos vastos e quase de todo desconhecidos territórios dos estados do Pará, sertões do Rio Negro, Mato Grosso e Cuiabá, ao estudo de etnografia das regiões percorridas, preparação dos produtos naturais destinados ao Real Museu de Lisboa, e, finalmente, fazer particulares observações filosóficas e políticas acerca dos objetos desta mesma viagem", como reza o decreto que o nomeou em 1783 (Tavares da Silva, 1947a, p. 126).

Sua expedição foi composta por um jardineiro-botânico, Agostinho Joaquim do Cabo, e por dois riscadores, José Joaquim Freire e Joaquim José Codina, que, com a ajuda da população local, mais precisamente de indígenas que deveriam ser treinados nos ofícios de preparadores de animais e aves, realizariam uma difícil viagem pelas terras interiores da América Portuguesa. Esta empresa respondia aos interesses impostos pela política lusitana. Claro está que, mais do que o abstrato progresso da ciência, tal iniciativa demonstra a grande visão estratégica portuguesa naquele final de século. O reconhecimento da natureza brasileira se enquadrava, pois, no projeto estatal que visava ao estudo dos três reinos, animal, vegetal e mineral, devidamente circunstanciado nas notícias pertencentes à história natural, ou seja, numa completa descrição geográfica de cada lugar, com vistas à exploração mais racional dos territórios coloniais (Ferraz, 1997; Nizza da Silva, 1999).

Aliado a esse interesse, não se deve perder de vista que os recentes tratados de limites assinados pelas duas coroas ibéricas exigiam de Portugal a necessária ocupação dos territórios fronteiriços conquistados de Espanha, requisito essencial para a efetiva incorporação destes à América Portuguesa, atendendo ao princípio de utipossidetis, que rezava nos tratados de Madri e de Santo Ildefonso. Este é o caso específico de parte do território amazônico e de toda a aurífica e diamantífera capitania 
de Mato Grosso e Cuiabá, o território alvo, no qual a expedição filosófica enviada ao interior do Brasil deveria desenvolver seus trabalhos.

A expedição Ferreira legou-nos inúmeras memórias sobre flora, fauna, minérios, populações indígenas; herbários, animais empalhados, amostras de madeiras, coleções mineralógicas, além de centenas de desenhos e aquarelas e uma riquíssima coleção etnográfica sobre populações indígenas, além de precisas informações sobre os territórios recém-ocupados pelos lusitanos na raia fronteiriça entre as duas Américas ibéricas. É evidente que esta viagem cumpriu os objetivos exigidos pelo Estado lusitano à sua empresa naturalista: parte do interior da América Portuguesa foi esquadrinhada e reconhecida.

Muito já se escreveu sobre a não divulgação dos resultados dos trabalhos desta expedição e sobre a dispersão do seu legado, iniciada com o saque perpetrado pelos franceses sob o comando do marechal Junot, em 1808, durante a penetração napoleônica na península ibérica, quando parte significativa dos trabalhos de Ferreira e seus companheiros, além de animais e herbários, passaram às mãos de Étienne Geoffroy Saint-Hilaire. Entretanto, mesmo com as significativas perdas oriundas de traslados, saques e incêndios, ainda se conserva um valioso legado em acervos de instituições portuguesas e brasileiras, que só o esforço de equipes multidisciplinares pode trazer a público; parte dele, infelizmente, em péssimo estado de conservação.

Hoje é sabido, como demonstrou Simon (1983) em seu estudo sobre as expedições portuguesas do século XVIII, que não foi somente SaintHilaire quem se beneficiou dos trabalhos realizados por Ferreira. Através do intenso intercâmbio que museus e jardins botânicos europeus mantinham entre si, estudiosos como o inglês Joseph Banks, o espanhol Casimiro Gómez Ortega e mesmo Humboldt também puderam ter acesso aos materiais produzidos pelo árduo trabalho do naturalista baiano.

Contudo, a maior difusão dos resultados desta Viagem Filosófica vai se dar em meados do século XIX, quando, de formas diferenciadas, trazem-se a público séries documentais e dados da biografia de Ferreira e sobre a sua empresa naturalista. Mais recentemente, temos visto estudos monográficos revisitando documentos e lançando luzes sobre a biografia de Alexandre e sobre os trabalhos que realizou, circunstanciando-os no contexto sociocultural e político nos quais estes se inserem (Simon, 1983; Almaça et alii, 1992; Mittermeier et alii, 1992; Rodrigues de Areia et alii, 1991). Porém, na quase totalidade, esses trabalhos têm dado ênfase à primeira fase da sua estada na Amazônia brasileira, notadamente à sua permanência nas então capitanias do Grão-Pará e Rio Negro, onde efetivamente passou o tempo mais dilatado da viagem e durante o qual coletou um riquíssimo acervo e escreveu diários e inúmeras memórias.

A segunda etapa, que compreende o trajeto percorrido entre os rios Madeira, Mamoré e Guaporé até as terras confinantes do território lusitano, na então capitania de Mato Grosso e Cuiabá, é surpreen- 
dentemente pouco conhecida e muito menos estudada, como bem observou Simon (1983, p. 41). Este dado chama particular atenção, uma vez que a capitania, naquele momento, era uma das meninas dos olhos do Estado português, por se tratar de um espaço recém-ocupado dos espanhóis, por ser limite com o Vice-Reino do Peru e, mais ainda, por ser rica em ouro e diamantes.

Esta preferência dos pesquisadores por estudar os trabalhos que a Viagem Filosófica desenvolveu nas capitanias do Rio Negro e GrãoPará, quiçá se justifique a partir da documentação existente. Na primeira etapa, Ferreira descreveu suas jornadas cotidianas em seguidos diários; para os caminhos realizados em Mato Grosso, tais anotações são desconhecidas. Também, comparativamente, a produção de imagens sobre Mato Grosso é consideravelmente menor. Enquanto a viagem pelas capitanias setentrionais está documentada em quase dois mil desenhos e aquarelas, até onde sabemos, os riscos dedicados à área noroeste somam aproximadamente duas centenas.

Mas, apesar de não contar com igual abundância de documentação, o acervo referente à viagem por Mato Grosso e Cuiabá permite acompanhar e compreender os passos desta empresa científica. A correspondência trocada entre o naturalista e as autoridades lusitanas, as diversas memórias, assim como os desenhos e aquarelas deixados pelos riscadores possibilitam afirmar que nesta capitania a Viagem Filosófica, embora tenha realizado coletas próprias de história natural, teve como principais objetivos as questões mineralógicas e o reconhecimento estratégico da raia fronteiriça com os territórios castelhanos, como busco demonstrar neste artigo. Para tanto, valhome das imagens descritas por Ferreira e das desenhadas por seus acompanhantes.

\section{As terras molhadas da capitania de Mato Grosso e Cuiabá}

No contexto da história brasileira, os territórios interiores que hoje compõem a região Centro-Oeste têm feições mais singulares, pois só em meados do século XVIII começaram a ser incorporados à América Portuguesa, pelas investidas dos bandeirantes paulistas. Com a violência que caracterizava seus atos, estes 'portugueses do Brasil', os bandeirantes, na busca de índios e ouro, subiam os rios alto-paraguaios e, através do Cuiabá, alcançavam o território Bororo onde, à superfície do solo, encontravam ouro, dando início à sua conquista em 1719. Logo se fundou o Arraial do Cuiabá, que alguns anos depois se transformaria em Vila Real do Bom Jesus do Cuiabá, sujeito à distante capitania de São Paulo.

Como em qualquer outra área mineradora, ali também a febre de riquezas atraiu centenas de aventureiros, que mais e mais adentraram o interior em busca de novas lavras, expulsando os indígenas e que, de maneira precária, criaram núcleos de povoamento. O eixo minerador, 
que inicialmente se localizava nas terras banhadas pelos rios altoparaguaios, deslocou-se no sentido oeste, fazendo surgir novos arraiais no vale do Guaporé, bacia amazônica, região então conhecida como Mato Grosso. Vale lembrar que, pelo menos nominalmente, estes territórios eram castelhanos.

Na década de 1750 e já na vigência do tratado de Madri, tentando garantir os ricos territórios conquistados, Portugal pôs em prática uma agressiva política de ocupação e, desprezando o seu maior núcleo populacional no Cuiabá, fundou Vila Bela da Santíssima Trindade, no vale do Guaporé, para ser a capital da récem-criada capitania de Mato Grosso e Cuiabá (1748). Às faldas das missões jesuítas espanholas, em território chiquitano, a capital situava-se em um lugar de total insalubridade, porém fundamentalmente estratégico. Para governar a nova capitania foram nomeados homens da mais nobre estirpe lusitana. Estes, orientados pela corte, promoveram uma vigorosa política de ocupação e defesa, plantando fortificações, presídios, povoações, vilas e arraiais por toda a aurífera raia fronteiriça, tanto na região do Guaporé como na banhada pela bacia paraguaia.

Ao tempo da passagem da Viagem Filosófica, a capitania de Mato Grosso e Cuiabá, na avaliação dos demarcadores de limites portugueses, era "uma das mais importantes de todo o Brasil, tanto pela sua extensão e pelas sabidas, mas ainda intactas riquezas, que guardam os seus vastíssimos sertões, como por ser fronteira ao vasto, populoso e rico Peru" (Ferreira e Almeida Serra, 1874). Ocupava uma superfície de 65 mil léguas quadradas — o equivalente a dois milhões e 340 mil quilômetros quadrados - terras que hoje fazem parte dos estados brasileiros de Rondônia, Mato Grosso e Mato Grosso do Sul. Excluindose a população indígena, que não consta nos levantamentos da época, neste extenso território vivia uma população de apenas 22 mil almas, sendo que mais da metade, exatos 12 mil, eram escravos.

A base econômica era a exploração mineral, tanto de ouro como de diamantes, extraídos de forma rudimentar nas diferentes lavras, principalmente na região do Cuiabá e seus arraiais auríferos, no Alto Paraguai diamantífero e nas ricas minas do Guaporé. Contudo, algumas fazendas de gado já estavam em pleno funcionamento e a capitania também possuía alguns engenhos de cana-de-açúcar e pequena produção de outros gêneros voltados para a subsistência.

Para se comunicar com o litoral, Mato Grosso contava com duas vias fluviais e uma terrestre, todas longas, difíceis e perigosas. Os caminhos fluviais poderiam levar a São Paulo, via bacia alto-paraguaia, ou ao Pará, através dos rios amazônicos. Apesar de mais rápida, esta via não era menos perigosa e acidentada que as outras; cruzava-se a cachoeira do rio Guaporé, as cinco do Mamoré e as 12 do Madeira, convivendo com febres durante todo o percurso.

A maior preocupação dos administradores desta distante capitania era a garantia dos territórios auríferos conquistados aos vizinhos 
castelhanos, principalmente no vale do Guaporé pela proximidade com os estabelecimentos espanhóis que ficavam ao poente, ou seja, com as missões de Moxos, situadas em rios que deságuam no Guaporé e habitadas, como Mato Grosso, por cerca de 22 mil almas.

Pouco antes da chegada de Ferreira, em 1786, os territórios matogrossenses haviam sido palmilhados pelos comissários da terceira partida demarcadora de limites. Luís de Albuquerque de Melo Pereira e Cáceres, o então capitão-general de Mato Grosso, homem de vasto saber e invejável percepção estratégica, havia incumbido os engenheiros, astrônomos e matemáticos encarregados da demarcação de reconhecerem as verdadeiras condições de defesa da capitania. O resultado foi apresentado num minucioso estudo, através do qual as autoridades lusitanas tomaram conhecimento de que, embora o Guaporé tivesse condições de conter um possível ataque castelhano, os rios pantaneiros se ofereciam como largas portas ao livre acesso dos vizinhos, caso estes quisessem chegar às ricas minas de ouro e diamantes do Cuiabá e do Alto Paraguai. Para uma ocupação efetiva era necessário, portanto, o imediato reconhecimento dos lugares assim como suas potencialidades. É justamente em meio a estes acontecimentos que vamos compreender a presença da Viagem Filosófica de Ferreira entre rios e terras mato-grossenses.

\section{De Barcelos a Vila Bela: rios, cachoeiras e febres}

Em novembro de 1786, Ferreira e seus companheiros, o jardineirobotânico Agostinho Joaquim do Cabo e os riscadores José Joaquim Freire e Joaquim José Codina, estavam na Vila de Barcelos. Haviam terminado uma fase dos seus trabalhos e esperavam ali as novas decisões de Lisboa sobre o destino a seguir: poderiam continuar na região Norte, entrando pelo Japurá, ou descer o Negro, rumo ao Madeira. Mas, o que Ferreira realmente queria era retornar a Portugal, porque, como explica ao ministro Martinho de Melo e Castro, "quase estão findos os três anos, que um só naturalista pode trabalhar em tão diferentes repartições"; e esclarece com preocupação: "quanto mais se prolongar a coleção dos produtos, mais se retardará depois o conhecimento individual de cada um no confuso caos de milhares de produções diversas", mas, como fiel servidor também ressalva: "V. Exa. porém resolverá o que for servido" (Lima, 1953, p. 160). De fato, há anos a expedição percorria rios e terras das capitanias do Grão-Pará e Rio Negro, das quais enviou a Lisboa fartas coleções de história natural, memórias, além de desenhos e objetos.

Ao sair de Portugal em 1783, Alexandre Rodrigues Ferreira trazia claras instruções do roteiro a seguir: os "desconhecidos territórios dos estados do Pará, sertões do Rio Negro, Mato Grosso e Cuiabá” (Tavares da Silva, 1947b). Passados três anos, no entanto, pairava a incerteza. A abundante correspondência trocada pelo naturalista com o ministro 
Martinho de Melo e Castro e com o governador do Rio Negro, João Pereira Caldas, atesta o grau de desgosto que esta indecisão lhe trazia e, ao mesmo tempo, as cartas trocadas com esse capitão-general bem demonstram a falta de autonomia do governo local, que repetidamente negava a Ferreira uma decisão, deixando-o na dependência absoluta das decisões e ordens vindas de Lisboa (Lima, op. cit., p. 213). Só em finais de 1788 chegaram ao Pará as reais ordens estipulando os caminhos e objetivos para a nova etapa da viagem. Ferreira e seus companheiros deveriam seguir pelo rio Madeira com destino à capitania de Mato Grosso e Cuiabá, para a qual, mais que o reconhecimento da fauna e da flora, as instruções de Lisboa priorizavam o reino mineral ou, nas palavras do naturalista, "uma viagem mineralógica".

Ferreira deveria tomar o caminho fluvial que ligava a capitania do Grão-Pará à de Mato Grosso, cujo trajeto era bastante conhecido e descrito em várias relações, desde finais de 1740. Exigia-se da expedição não apenas o transcurso dos rios, mas que viesse a realizar simultaneamente uma análise daqueles lugares e uma documentação visual de todo o trajeto, o que implicava uma viagem bem mais demorada.
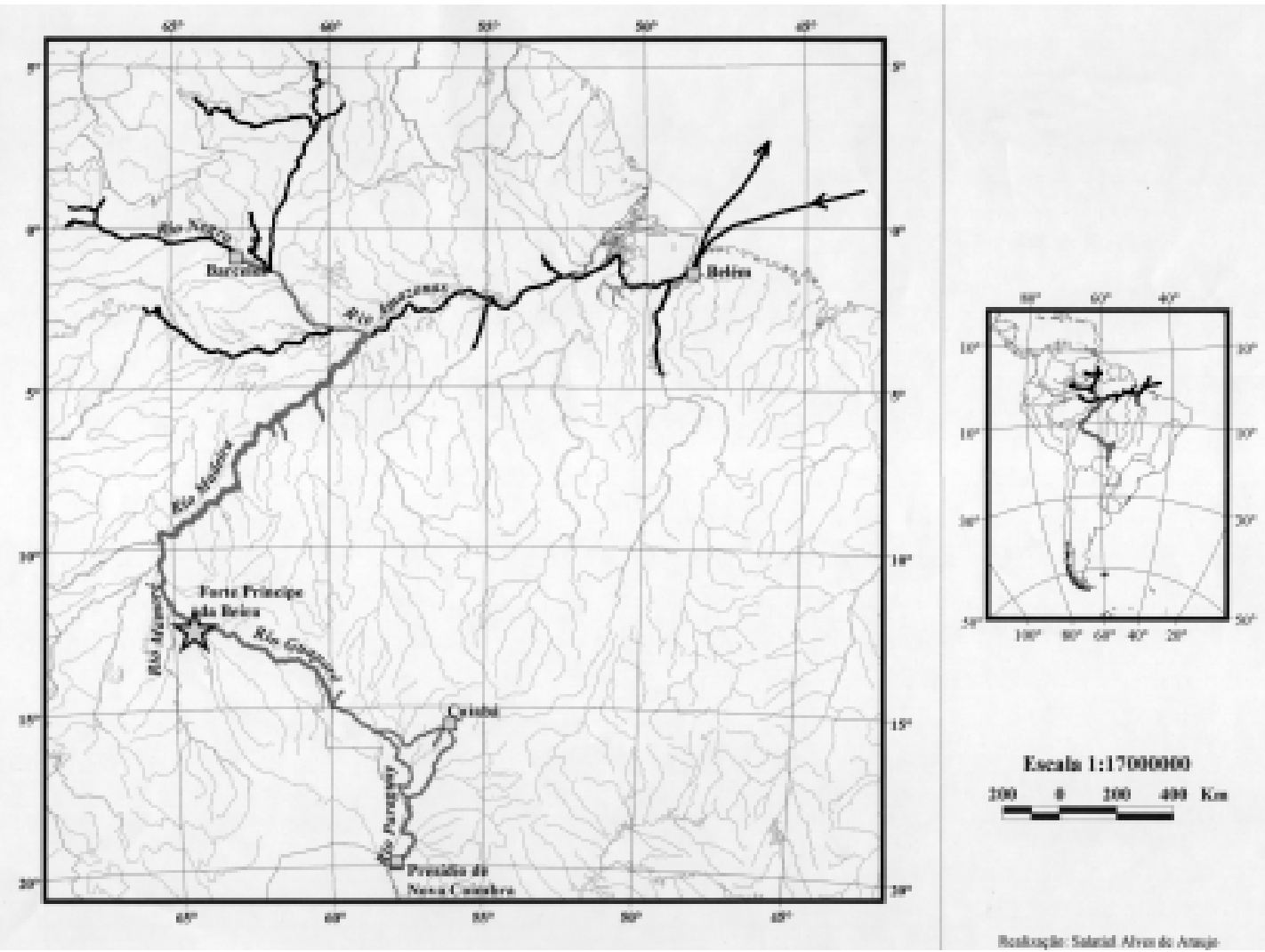

Roteiro da Viagem Filosófica (1783-92). 
Os preparativos consumiram mais oito meses entre organização e arranjos. Pensou-se em tudo, da botica às dúzias de galinhas destinadas ao sustento dos doentes e aos milhares de quilos de farinha e demais tipos de alimentos com as necessárias medidas de conservação e constante reposição. Pensou-se também nos 'remédios espirituais', para os quais se solicitava a presença de um capelão provido de "competente altar portátil, de alguns cubos de bem examinadas e reparadas hóstias, de vinho, e de algumas libras de cera de velas, para tudo servir ao exercício do seu ministério".

Novas embarcações rigorosamente adequadas às necessidades dos trabalhos naturalistas foram construídas; porém, a grande dificuldade consistia em arregimentar uma tripulação. Não se conseguiam os índios remeiros. As viagens entre Pará e Mato Grosso aterrorizavam a população, principalmente pelo alto índice de óbitos: quando não morriam durante a viagem, faleciam "depois de recolhidos às próprias povoações, pelo que a elas chegam infeccionados das costumadas moléstias", segundo relato dirigido ao governador de Mato Grosso. Com intenção de amenizar estas condições, uma complexa rede de apoio foi montada. Todos os núcleos populacionais do trajeto, desde a Vila de Barcelos, localizada às margens rio Negro, até Forte Príncipe da Beira, última parada antes de chegar a Vila Bela, foram informados da passagem da expedição e as autoridades locais instruídas "para acudir, com os socorros de gente, e de mantimentos, que deprecar, segundo as urgências que experimentar" (Lima, op. cit., pp. 242, 251, 250).

Finalmente, nos últimos dias de agosto de 1788, os barcos da Viagem Filosófica começaram a descer o rio Negro, daí ao Amazonas; através deste penetraram no Madeira, chegando à capital de Mato Grosso no início de outubro de 1789. Foram 13 meses e 18 dias de viagem, sendo que, destes, sete e meio "foram aplicados a exames, e coleções" e os demais "se empregou em viajar" (idem, ibidem, p. 295). Através do Roteiro das viagens, que fez pelas capitanias do Pará, rio Negro, Mato Grosso, e Cuiabá, Alexandre Rodrigues Ferreira, guardado na Biblioteca da Ajuda (ms. 51, VI, 46-15), é possível acompanhar quase passo a passo as andanças fluviais desta expedição. Parte dela pode ser vista nos desenhos e aquarelas que compõem o segundo volume de imagens guardado no Museu Bocage. O cotidiano pode ser reconstruído através das informações contidas na correspondência mantida com os governadores de Pará e Mato Grosso.

Durante o transcurso pelos rios, além das dificuldades naturais oferecidas pelas tantas cachoeiras, Ferreira teve que enfrentar deserções e rebeliões dos índios remeiros - o que afetava sobremaneira a marcha da viagem - , além da falta de alimentos e as esperadas doenças. $\mathrm{O}$ primeiro que, "logo à entrada do rio Mamoré, enfermou gravemente de sezões, foi o desenhador Joaquim José Codina”. Depois, já no forte Príncipe da Beira, foi a vez de Ferreira, "juntamente com o outro desenhador José Joaquim Freire”. Segundo conta o naturalista, a doença 
chegou a tal extremo que ambos tiveram que ficar "sepultados no barreiro do sítio dos Garajuz", fazendo referência com este termo a uma das formas de cura então usada naquelas remotas paragens. A situação das enfermidades ganhou tal vulto que os desenhadores não mais puderam documentar a viagem: "Freire foi o que mais sofreu, não houve moléstia que não sobreviesse, foram sezões, corrução, sarna, disenteria etc." Contudo, o jardineiro-botânico, que parecia ser o mais forte, pouco depois de chegar a Vila Bela, não resistindo às febres da terrível corrução, faleceu nos braços do seu chefe (Tavares da Silva, 1947b, p. 339).

Chegar àquela capital não lhes trouxe maior alívio: a cidade "se achava atacada das horrorosas epidemias de catarrais, sarampo, garrotilhos, pontadas e disenterias". A situação era calamitosa, nem mesmo os animais foram poupados: "Pelos matos, morreram antas, porcos, veados, bestas muares e cavalares e até mesmo aves "(Lima, op. cit., pp. 295-6).

Vila Bela foi construída em terreno alagadiço e sua insalubridade sempre conhecida; porém, a escolha do sítio estava ligada à proximidade das missões de Chiquitos e Moxos, obviamente por questões de defesa. No tempo da visita de Ferreira, aquela localidade contava com aproximadamente sete mil almas e, a julgar por suas palavras, a situação era calamitosa: houve "dias em que no cemitério desta vila se sepultaram nove, e dez falecidos; e desde os fins de agosto próximo passado, até princípios de janeiro do corrente nos dois pequenos arraiais de Santa Ana, e Pilar, 75 pessoas" (idem, ibidem, p. 295). Segundo o viajante, foi em 1789, o mesmo ano da sua chegada, que o sarampo se apresentou naquela região pela primeira vez e logo virou epidemia, matando 154 homens e 47 mulheres, em apenas quatro meses.

Por suas anotações, podemos conhecer um pouco da capital de Mato Grosso. Vila Bela tinha um traçado irregular, com ruas retas e estreitas sem calçamento, onde os porcos prazerosamente chafurdavam na lama. Suas casas eram térreas, com parede de adobe dobrado, cobertas de telhas-vãs e "todas elas, ou simplesmente aterradas, ou ladrilhadas de tijolo"; as janelas pouco rasgadas e comumente defendidas por gelosias, o que na avaliação de Ferreira transformava seu interior em câmaras escuras e tristes, além de impedirem o livre acesso de ar. Não havia hospital e nem sequer uma botica provida de remédios caseiros; o cirurgião que ali estava pertencia à terceira partida demarcadora e logo seguiria viagem, sendo os habitantes atendidos por charlatães (Ferreira apud Fontes, s. d., pp. 49, 51; Ferreira, c. 1790).

Pelo que se abstrai dos relatos, em Mato Grosso não havia possibilidade de se estar sadio; os que ali moravam, quando não conviviam com as sazonais epidemias, conviviam com "as doenças de todo o tempo" que a todos vitimavam: a obstrução, a hidropisia, o escorbuto, os espasmos, as hemorróidas e a sarna. O resultado era morte e despovoação, pois, como observou o naturalista, todos os dias 
enterrava-se um "punhado de homens neste cemitério do Brasil, a que se dá o nome de Mato Grosso" (idem, c. 1790).

Em Vila Bela, os membros da expedição viram chegar João de Albuquerque Melo Pereira e Cáceres, irmão de Luís, que o substituiria à frente da capitania e na gerência da Viagem Filosófica. Trazia consigo uma carta do ministro Martinho de Melo e Castro, na qual, entre outros assuntos, tratava das novas instruções; mantinha a ênfase nas questões mineralógicas, mas acrescentava: "não deixará o dito doutor Alexandre de examinar a caverna de que trata o diário" (Melo e Castro, 1788). O parágrafo do diário a que se refere a carta descreve uma gruta que os demarcadores descobriram junto ao presídio de Nova Coimbra. Já não bastava chegar às minas do Cuiabá; Ferreira e seus companheiros teriam que descer o rio Paraguai, percorrer o labirinto das águas do Pantanal e chegar até o limite noroeste das novas terras portuguesas, com a finalidade clara de realizar uma avaliação do estado da fronteira.

\section{A Viagem Filosófica à capitania de Mato Grosso e Cuiabá}

Logo que se restabeleceram, Ferreira e seus companheiros, desfalcados do jardineiro-botânico, dirigiram-se à serra de São Vicente, localizada no entorno de Vila Bela. Ali estavam os oito arraiais auríferos que deveriam ser examinados. Percorrendo lavra a lavra, como rezavam suas instruções, o naturalista analisou e recolheu amostras dos diferentes tipos de ouro. Suas observações foram registradas no 'Prospecto filosófico da serra de São Vicentee seus estabelecimentos', um minucioso relatório no qual descreve a qualidade dos diversos tipos de ouro, as formas de extração, assim como as condições gerais de cada lugar, fornecendo dados sobre população, condições de saúde e formas de produção agrícola. Discorre também sobre as madeiras e outros recursos naturais ali encontrados, sugerindo maneiras de os explorar racionalmente, inclusive fazendo observações sobre como evitar o desmatamento.

No seu entender, todas aquelas lavras eram mal exploradas, havendo subaproveitamento do mineral. Não havia tecnologia adequada e aos mineradores só interessava o ouro puro e superficial. Analisando as formas de extração, o naturalista sugere o uso do mercúrio para uma melhor amalgamação do ouro fino, "método em que bem pouco ouro se perde como estão experimentando os mineiros europeus".

De volta a Vila Bela, preparou-se para a viagem por terra para o Cuiabá, via Vila Maria (Cáceres). No caminho, deveria visitar os arraiais auríferos de Lavrinha, São Pedro d'El-Rei (Poconé) e minas circunvizinhas, Cocais e Lavras do Jessé, analisando-as e recolhendo amostras para as reais coleções portuguesas. Contudo, não poderia visitar a região diamantífera do Alto Paraguai. Apesar da insistência do naturalista, João de Albuquerque negou-se a interferir nas determinações vindas da corte, que proibiam terminantemente visitas a esse distrito diamantífero. 


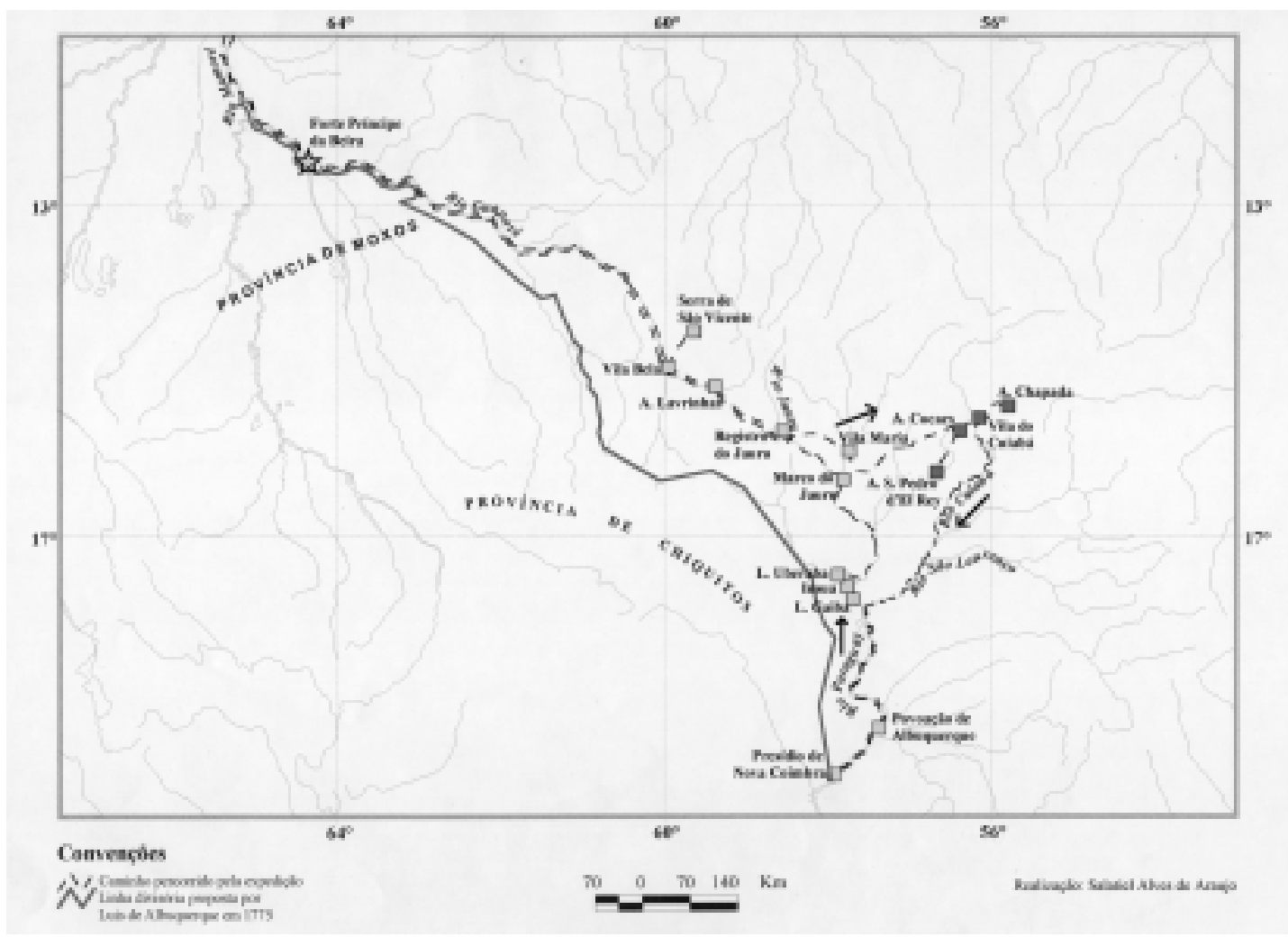

Roteiro da Viagem Filosófica na capitania de Mato Grosso (1789-92).

A julgar pelo acervo iconográfico desta expedição, guardado no Museu Bocage, foi a lavra de ouro no arraial de São José dos Cocais, nas cercanias de Cuiabá, que mais atenção mereceu da Viagem Filosófica. Codina e Freire registraram em quatro aquarelas as diferentes etapas do trabalho ali realizado, desde o desmonte do barranco até a lavagem do ouro. Essas aquarelas, todas inacabadas, são sem dúvida um dos primeiros registros visuais da forma de trabalho numa lavra de ouro no interior do Brasil. Curiosamente, a lavagem do metal era realizada em uma canoa expressamente adaptada para essa função, ficando a planta desta máquina de minerar também detalhada em desenho.

Depois de concluir o trabalho nos arraiais mineradores, a expedição dirigiu-se ao Pantanal, com destino ao presídio de Nova Coimbra, onde "jazem, ou jaziam dantes tanto o vieiro de pedra dendrites, como a caverna decorada com estalactites ... que o Exmo. senhor Martinho de Melo e Castro, agora determina muito expressamente todo o possível reconhecimento, e indagações".

A exemplo dos outros roteiros já realizados, esta viagem também foi preparada a fim de responder à singularidade do lugar. Construíram-se batelões, ou ubás, próprios para navegação nestes rios, um tipo de canoas indígenas esculpidas no interior do tronco inteiriço de uma 


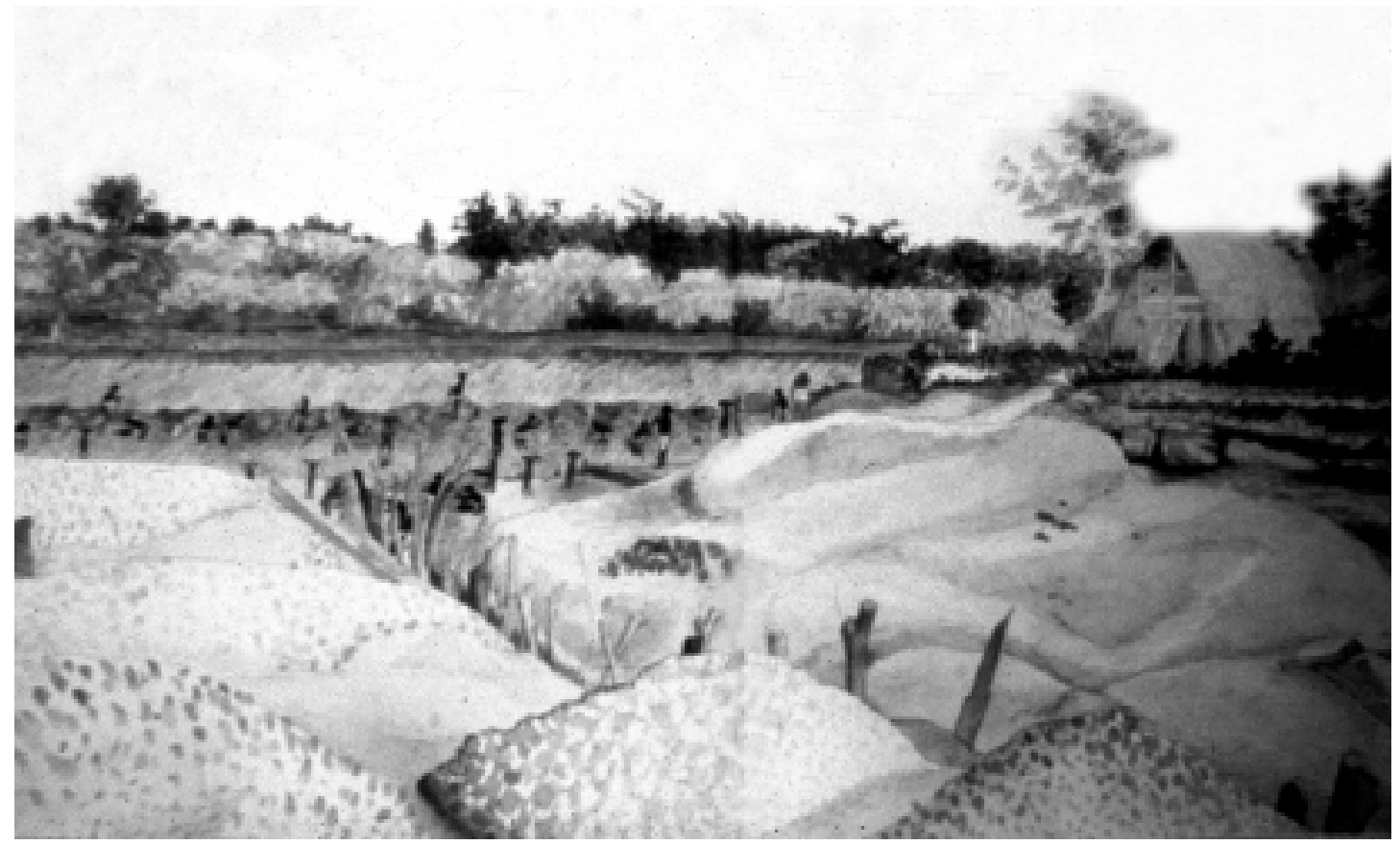

Prospecto do desmonte de terra da Lavra do Ouro do sargento-mor José Paes Falcão das Neves, no arraial de São José dos Cocais da Vila do Cuiabá” (sem autor, 1791). Aquarela inacabada sobre papel $38,3 \times 19 \mathrm{~cm}$ (Lisboa, Museu Bocage).

${ }^{1}$ Os nomes indígenas estão no singular e grafados conforme a 'Convenção para a grafia dos nomes tribais da Reunião Brasileira de Antropologia de 1953. árvore, que também foram documentadas pelos riscadores. Como era tempo de cheia e o Paraguai já se havia espraiado mais extensamente, dotou-se a expedição de uma canoa-cozinha. E, para reforçar a segurança, acrescentou-se uma guarnição militar para o caso de ataque dos Guaikurú ou dos Paiaguá. ${ }^{1}$

O presídio de Nova Coimbra localizava-se no extremo da fronteira sudoeste da capitania, num terreno em disputa com os espanhóis, e constituía uma das grandes preocupações para os governadores, tendo sido concebido para ser o baluarte mais avançado sobre o rio Paraguai. Ao mandá-lo construir, Luís de Albuquerque havia indicado o lugar onde aquele grande curso fluvial se estreita, conhecido como Fecho dos Morros. O capitão-general projetava um posto militar que ao mesmo tempo garantisse o caminho fluvial entre São Paulo e as minas do Cuiabá, fosse ponto de defesa a qualquer investida castelhana e ainda impedisse o passo dos guerreiros Guaikurú e Payaguá. Porém, o encarregado da tarefa, pouco conhecedor dos meandros do Paraguai, atrapalhou-se na identificação geográfica e, em 1775, fundou o presídio junto a uma outra elevação, em local totalmente vulnerável. Esta vulnerabilidade foi posta às claras com os levantamentos realizados pelos demarcadores de limites em 1786, que ali, como se não bastasse, descobriram uma fabulosa gruta nas entranhas do monte localizado atrás do presídio. 
Pelo que se depreende da documentação, a ida do naturalista a este sítio tinha o objetivo claro de analisar as condições do lugar e, especialmente, a recém-descoberta gruta do Inferno. As observações de Ferreira foram passadas a João de Albuquerque na carta que datou no canal da boca da lagoa Uberava, em 5 de maio de 1791. Nela o viajante é taxativo: "até eu, que de fortificações nada entendo, notarei os inauferíveis defeitos que aquela tem", e enumera um a um os erros desta construção e da inadequada localização. Chega ao ponto de dizer: "por mais guarnecido que seja semelhante passo, nenhuma necessidade têm os espanhóis de por ele passarem, caso queiram subir aos nossos estabelecimentos". Ou seja, aquela guarnição militar, fundada com o claro objetivo de servir de contraforte aos possíveis ataques castelhanos, de nada adiantava. Quanto à gruta, observa que é um ótimo lugar para esconderijo do inimigo: dentro dela pode "aquartelarse à vontade um corpo de até mil homens" (Ferreira, 1791).

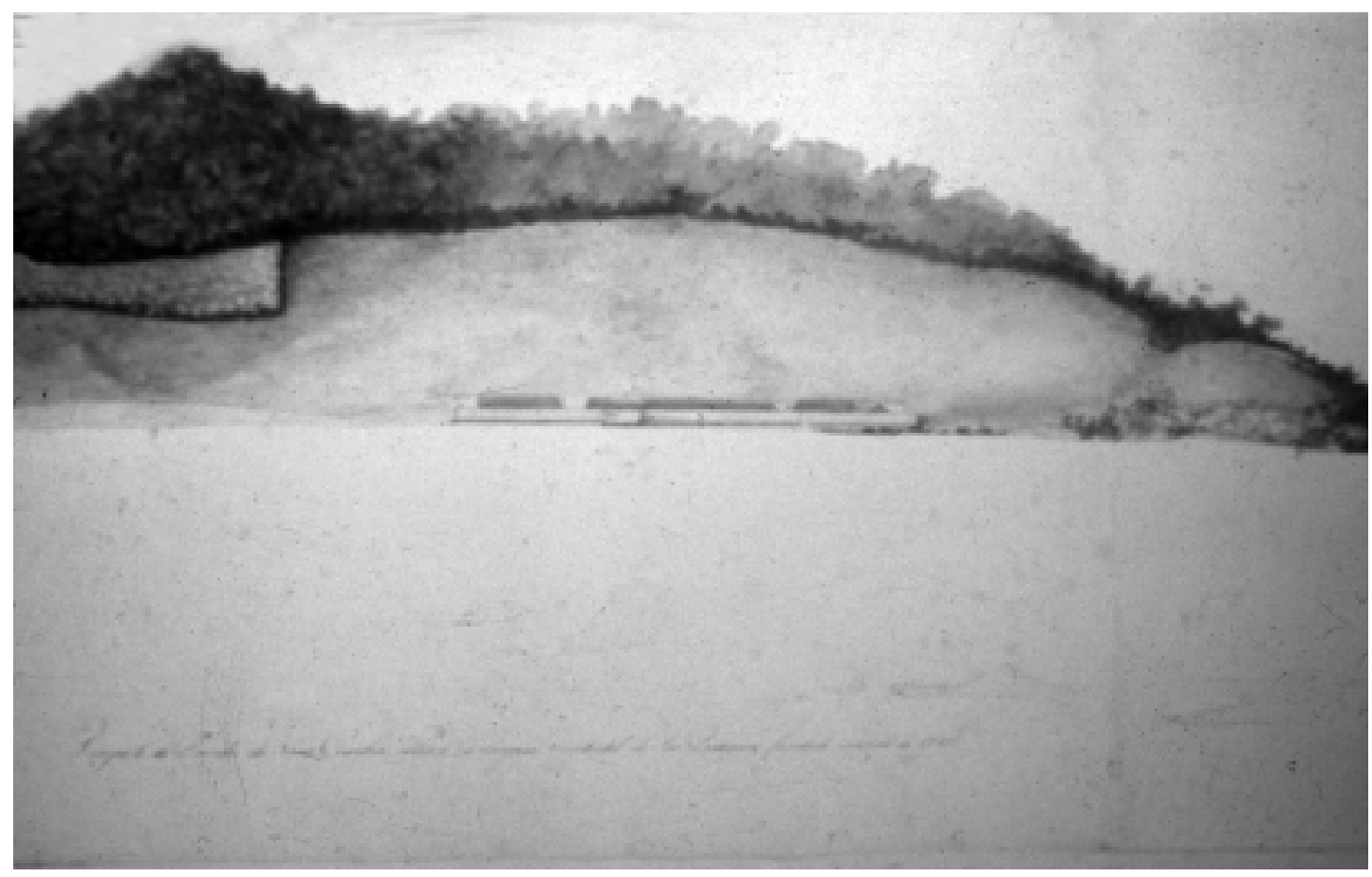

Prospecto do presídio de Nova Coimbra, situado na margem do rio Paraguai, fundado em 1775 (sem autor, 1791). Aquarela inacabada sobre papel 40×18cm (Lisboa, Museu Bocage).

Ainda no presídio, a expedição teve a grata surpresa de encontrar 11 índios da tribo dos Guaikurú, que naquele momento estavam aceitando os chamamentos das autoridades lusitanas, que queriam fixá-los num aldeamento nas terras contíguas àquele acampamento militar. Ferreira, então, aproveitou para fazer observações sobre 
${ }^{2}$ Carvalho (s. d., p. 14) e Simon (1983, p. 45) afirmam que Codina faleceu em Mato Grosso, em 1791, tendo sido sepultado no barreiro do sítio dos Guarujus, mas a carta de Francisco de Souza Coutinho a Martinho de Melo e Castro (15. 10. 1792) demonstra que Codina voltou com Freire e Ferreira para Portugal. Penso que os citados autores fizeram uma interpretação errônea de alguma fonte que, infelizmente, não citam. Ferreira, como já referido, usa a expressão "sepultar no barreiro", para indicar uma forma de cura então usada na região. estes índios cavaleiros, que desde o início do século XVIII atormentavam não só os viajantes que cruzavam as águas pantaneiras nas suas anuais monções entre São Paulo e Cuiabá, mas também os moradores de lugares mais distantes, como Cuiabá e Vila Maria.

Saindo do presídio de Nova Coimbra, a expedição deixou "a madre do rio, para navegar pelos pantanais encostados às serras do Paraguai”, chegando à povoação de Albuquerque. Com o mesmo olhar perscrutador, Ferreira analisou as condições de defesa. Para ele, em caso de "se dever mudar o presídio, é aquela uma das mais adequadas situações que oferece o Paraguai". Albuquerque era "uma povoação fechada à maneira de um grande pátio, quase três vezes mais comprido, do que largo". Este lugar abrigava uma população de 152 pessoas. Para o naturalista, Albuquerque tinha ótimas condições agrícolas, era rica em madeiras para construção e tinturaria, em pedra, cal e barro para uma grande olaria. Porém, ali vivia uma população sem paixão pelo trabalho, que lhe pareceu quase morta de fome.

Depois das indicações de Albuquerque, faltava-lhe seguir as dos demarcadores e, na área mais inundável do Pantanal, reexaminar as três grandes baías pantaneiras, Gaiba, Uberava e Mandioré; alcançar a boca do Jauru; investigar as estranhas jazidas de pedra calcária de cor negra, e de alguns mármores, ágatas; e, finalmente, dirigir-se a Vila Bela (Lima, op. cit., p. 311).

Realizou seu trabalho satisfatoriamente: em 26 de junho já encontramos os expedicionários nesta capital. Durante três meses, ali permaneceram organizando suas coleções, redigindo memórias e preparando-se para novamente cruzar os rios amazônicos com destino à cidade do Pará e dali, para Lisboa. No caminho, os desenhadores ainda deveriam tirar "os prospectos das cachoeiras do rio Madeira na ocasião de maior vazante das suas águas” (idem, ibidem, p. 350). Em janeiro de 1792, já estavam na cidade do Pará e, em outubro, Alexandre Rodrigues Ferreira com os dois desenhadores José Joaquim Freire e Joaquim José Codina embarcaram no navio Príncipe da Beira, que os levaria de volta a Portugal. ${ }^{2}$

\section{Algumas observações sobre o legado}

Das andanças por terras e águas da capitania de Mato Grosso, a Viagem Filosófica legou algumas memórias, várias relações sobre os envios de produtos naturais dos três reinos, mais de uma centena de imagens em desenhos e aquarelas, e um significativo acervo etnográfico recolhido principalmente entre os Guaikurú. Neste artigo, serão examinados com mais vagar seus escritos sobre as enfermidades de Mato Grosso e sobre os índios Guaikurú, assim como algumas imagens produzidas pelos riscadores.

As questões ligadas às condições de saúde dos habitantes de Mato Grosso estão presentes de forma dispersa em quase todas as 
memórias e cartas que Ferreira escreveu durante sua estada nesta capitania. Como os demais visitantes que estiveram entre as bacias amazônica e alto-paraguaia, este viajante também assinala a diferença do clima, definindo a região do Guaporé como insalubre e a do Paraguai como de ar saudável e reparador. As graves enfermidades que sofreu, principalmente no Arraial de Lavrinhas, assim como as que observou nos habitantes dos diferentes lugares, desde a sua entrada no Madeira, levaram-no a analisar o estado de morbidez em duas memórias específicas.

Certamente uma das grandes preocupações do governo colonial daquelas paragens eram as condições da viagem na rota fluvial que ligava Vila Bela ao Pará. Dela, em grande parte, dependia o escoamento do ouro, manutenção dos habitantes e segurança da fronteira. Como já visto, apesar dos grandes obstáculos naturais que a acidentada geografia dos rios impõe neste percurso, o maior entrave era a insalubridade dos lugares, que mantinha a viagem com um alto índice de óbitos. Tanto que a grande dificuldade encontrada por Ferreira no preparo da sua monção foi arregimentar índios para trabalharem como pilotos e remeiros.

Refletindo sobre isso, o naturalista escreveu 'Causa das doenças dos índios'; trata-se de uma minuciosa memória, na qual analisa as condições em que se davam as viagens entre as capitanias do Grão-Pará e Mato Grosso. Neste documento, de forma clara, Ferreira aponta, entre outras, as três principais causas das doenças: as "condições de trabalho, a nudez dos corpos e a corrupção dos alimentos", que seriam as responsáveis pela "devastação dos índios que remam em semelhante viagem". Como prova disto, observa: "os brancos, que fazem por ter o preciso e não passam pelos incômodos que eles, ainda que sejam acometidos das sezões não morrem tanto. E os soldados, que em todas as partes é ( $\mathrm{sic}$ ) gente pobre, só porque andam mais cobertos, cômodos e folgados, raras vezes falecem." Para Ferreira (s. d.), portanto, mais que o lugar, as causas do grande índice de mortes seriam fatores externos ligados às más condições do trabalho. E nesse sentido conclui, taxativo: "porque as providências de que eles (índios) necessitam para o futuro são de obras e não de palavras, sob pena de virem ficando despovoados os nossos estabelecimentos".

A sua memória mais conhecida sobre as questões de saúde da capitania é 'Enfermidades endêmicas da capitania de Mato Grosso'. Tal escrito surge de uma solicitação feita a Ferreira pelo governador João de Albuquerque. O naturalista começou a redigi-la em Cuiabá, aproveitando as horas do seu "descanso"; com o objetivo de "formalizar um tal ou qual diretório médico onde pudesse ver o curativo correspondente a cada uma das enfermidades endêmicas do país". Para tanto, buscou ajuda de moradores, no sentido de obter dados sobre o número de óbitos que tinha havido nos últimos anos, assim como as diferentes formas de contágio, tendo também 
consultado a literatura disponível (idem, ibidem). O resultado é um minucioso compêndio sobre as diversas doenças que assolavam Mato Grosso, com descrição de causas e sintomas e algumas observações de caráter político-social. As reflexões que ali desenvolve ajudam a conhecer as muitas doenças que infectavam e às vezes ainda infectam a Amazônia, com as respectivas formas de cura, tanto européia como americana.

Ambos os escritos apontam uma preocupação, por parte de Ferreira e também das autoridades, em entender as diversas doenças, buscando formas de minimizar seus efeitos e diminuir o alto índice de mortes e, conseqüentemente, a despovoação no espaço fronteiriço.

Quanto ao encontro de Ferreira com os Guaikurú, foi um feliz acaso. A distância e a difícil comunicação não permitiam que as autoridades administrativas acompanhassem os andamentos das negociações que o comandante do presídio tentava estabelecer com os índios cavaleiros. Ferreira não contava com uma relação amistosa com eles; tanto que, durante os preparativos da sua viagem pelo Pantanal, a expedição foi acrescida de 11 auxiliares comandados por um cabo, que formaram a guarnição militar, contra os gentios Guaikurú e Payaguá (Lima, op. cit., p. 340). A narração do encontro foi feita por Ferreira (1974) na 'Memória sobre os gentios aicurus', onde se lê: "ali tive o gosto de vê-los, quando cheguei, que eram 11 por todos, entre seis homens e cinco mulheres"; dentre estes o cacique Caimá, que já atendia pelo nome de João Queima de Albuquerque, e a "formosa tapuia, sua mulher", então denominada d. Joaquina Ferreira de Albuquerque. Segundo Ferreira, os Guaikurú haviam atendido aos chamamentos do comandante do presídio e estavam ansiosos por se aldearem nos terrenos contíguos àquela praça militar.

As informações passadas por Ferreira na sua memória foram conseguidas ou através de "uma negra crioula nossa" chamada Vitória, que os cavaleiros haviam capturado como escrava e que então lhes servia de "língua", ou foram passadas pelo capelão do presídio, João José Gomes da Costa, que já havia visitado os Guaikurú em sua aldeia. Assim sendo, parte da descrição de Ferreira é um relato de segunda mão. Conta-nos sobre o lugar onde os Guaikurú habitavam, tipo de arquitetura das suas casas, seus costumes religiosos, médicos e cerimônias fúnebres; sobre os desenhos corporais, a moda dos penteados das mulheres solteiras e casadas, das relações estabelecidas entre maridos e mulheres, prática do aborto, dos hábitos alimentares, dos utensílios e armas, das relações que mantinham com escravos, cavalos e índios vassalos, principalmente com os Guaná. Segundo estas informações, os Guaikurú tinham vida nômade, mas possuíam alguns alojamentos fixos: "eles vão situá-los nas serras circunvizinhas, quando com a enchente do rio, se inundam as campanhas adjacentes. Servem-lhes de quartéis de inverno, para onde se retiram os decrépitos, os inválidos, as mulheres pejadas e as paridas, que têm de criar seus filhos. Tudo o mais pelo 
tempo do verão são aldeias errantes, que se estabelecem, onde favorece o tempo e o lugar" (idem, ibidem, p. 79).

Talvez com o objetivo de ilustrar a memória escrita por Ferreira, os riscadores realizaram três diferentes representações deste povo: dois retratos, sendo um do chefe Caimá e o outro da formosa tapuia, sua mulher, cujos originais em aquarelas fazem parte dos fundos do Museu Bocage, em Lisboa. A Biblioteca Nacional do Rio de Janeiro possui cópias de ambos a nanquim, que apresentam significativas diferenças da matriz. A terceira imagem, guardada na mesma instituição, mostra uma cena do dia-a-dia: jovens mães com suas crianças, ao lado de anciões e muitos cavalos. Trata-se de uma cópia, cujo original ainda não foi possível localizar. Olhando-a, não é difícil reconhecer alguns trechos descritos por Ferreira na sua memória sobre estes índios. Como nem ele nem seus riscadores visitaram um acampamento Guaikurú, estamos diante de uma cena totalmente idealizada, a partir dos dados contados pelos dois informantes (ver Figura 6 à p. 988).

As três imagens dos Guaikurú são efetivamente as únicas de temática indígena que a expedição registrou na viagem pela capitania de Mato Grosso e Cuiabá. Isto cobra particular atenção, por se tratar de representações de povos indígenas de um lugar onde ainda hoje grande parte dos habitantes traz na face traços reconhecidamente indígenas.

Tendo atravessado tantos territórios habitados por outros povos indígenas, notadamente Pareci e Bororo, é significativo que Ferreira só tenha mandado representar índios Guaikurú, um povo guerreiro que, desde o início da penetração luso-brasileira na bacia alto-paraguaia, sempre foi visto como ameaça à soberania portuguesa no interior da América e de quem se temia uma possível aliança com os castelhanos. Neste contexto, é fácil entender o entusiasmo com que o naturalista escreveu ao governador e capitão-general João de Albuquerque:

Quanto ao gentio, persuado-me, que já pode V. Exa. aceitar as devidas felicitações, pelo vantajoso princípio, que tem dado o mesmo sargento-mor ao importante negócio da redução do Guaikurú. Redução, que tão grande serviço fez ela a Deus, como a S. Majestade, e ao bem público. A Deus, pelo considerável número de almas, que mediante o batismo, se podem fazer dignas da sua graça; à S. Majestade, por mais aqueles vassalos, que reduz à sua obediência, privando deles aos espanhóis, que em toda parte são muito maus vizinhos e ao bem público, pela segurança e liberdade do comércio, e navegação mercantil dos portos de beira-mar, para estas Minas (Ferreira, 1791).

Pouco tempo depois, encontramos Caimá, sua mulher e alguns outros Guaikurú em Vila Bela. Assinavam um tratado de paz e amizade com a coroa lusitana, representada pelo capitão-general de Mato Grosso. Nesse documento, o qual também Alexandre Rodrigues Ferreira assinou 
como testemunha, a nação Guaikurú reconhecia nominalmente a soberania da rainha d. Maria I. É nesse contexto que se deve entender o interesse de Ferreira por este povo. Os retratos do seu chefe e da mulher não são meras representações curiosas de personagens exóticos; constituem, isto sim, documentos iconográficos de suma importância nos quais se propõem deixar registrada a relevância dos retratados no momento em que estes, em nome da nação Guaikurú, capitulam.

Gostaria, ainda, de assinalar alguns aspectos relativos a outros registros visuais realizados por Joaquim José Codina e José Joaquim Freire durante a viagem à capitania de Mato Grosso e Cuiabá, de valor documental inexcedível. Trata-se de desenhos e aquarelas guardados no Museu Bocage: vistas, prospectos e plantas de vilas, arraiais, povoações e cachoeiras, relacionadas aos caminhos percorridos pela Viagem Filosófica entre os rios Madeira e Paraguai. Em algumas se indica o autor - Freire ou Codina — data de execução e o motivo representado. Dentre estas certamente duas são cópias, caso específico do 'Plano da Vila do Bom Jesus do Cuiabá', reprodução do desenho levantado por Ricardo Franco de Almeida Serra, e a 'Planta da antiga Vila Boa dos Goiases', lugar que nem a expedição nem aqueles riscadores visitaram. As demais folhas parecem ter sido feitas do natural.

Aqui mencionarei apenas as representações das 18 cachoeiras localizadas no trajeto entre Pará e Mato Grosso. De cada uma destas precipitações foram tomadas duas e às vezes três representações; uma sempre datada entre janeiro e março de 1789, ou seja, na viagem de ida, e outra invariavelmente datada em novembro, sem indicar o ano. As folhas realizadas em novembro pertencem à viagem de volta, marcada para coincidir com o período de maior vazante daqueles rios, justamente para que os desenhadores pudessem documentar visualmente a variação das águas em períodos distintos. As exceções são a vista da cachoeira Guajará-Mirim - a quinta do Mamoré — e a de Santa Rosa do rio Guaporé, datadas de outubro de 1791, ou seja, no retorno. Lembremos que na viagem de ida, ao realizarem este trajeto, Freire e Codina estavam tão enfermos que não tiveram forças para representá-las.

Em conjunto, estas vistas são monótonas, com uma quase invariável paisagem de águas imensas, barrancos, pedras e matas, sempre indicando a força e direção do rio. A monotonia é quebrada algumas vezes pela presença de homens que, em barcos, lutam contra a violência das águas.

Hoje olhamos estas aquarelas buscando os valores estéticos das paisagens representadas, que elas certamente possuem. Contudo, ao serem concebidas pelas hábeis mãos destes documentadores, tinham o objetivo primordial de detalhar da melhor forma possível o volume das águas e a força das correntezas, assim como as dificuldades de navegação enfrentadas pelos pequenos barcos; jamais foram concebidas como cenas de paisagens contemplativas. Buscava-se, isto sim, oferecer 
elementos que pudessem instruir como melhor se deslocar nestas águas acidentadas. Se as pusermos ao lado da memória 'Causas das doenças dos índios', teremos um quadro objetivo das reais condições em que se realizavam as viagens pela principal via de comunicação entre Mato Grosso e a metrópole lusitana. Tal conhecimento objetivamente visava contribuir para as condições de defesa e desenvolvimento da rica região.

Pelo exposto, vemos, pois, que as andanças de Alexandre Rodrigues Ferreira pela capitania de Mato Grosso e Cuiabá estão estreitamente ligadas às questões de reconhecimento do território fronteiriço e das potencialidades da riqueza mineral contida nas terras que Portugal havia conquistado dos vizinhos espanhóis. Nestas terras interiores, em que pese as remessas de amostra de produtos, animais e plantas, a Viagem Filosófica pouco realizou de atividades mais propriamente ligadas à história natural.

\section{REFERÊNCIAS BIBLIOGRÁFICAS}

\section{Fontes manuscritas}

Coutinho, Francisco de Souza

15. 10. 1792

Ferreira, Alexandre Rodrigues

5. 5. 1791

Ferreira, Alexandre Rodrigues

s. d.

Ferreira, Alexandre Rodrigues

c. 1790

Mello e Castro, Martinho de 30.11.1788

Vandelli, Domenico 1779

\section{Fontes impressas}

Almaça, Carlos et alii 1992

Carvalho, José

Candido de Mello s. d.
'Carta a Martinho de Mello e Castro'.

Belém, Biblioteca Nacional do Rio de Janeiro, ms. I - 11, 2, 24 nº 1.

'Carta a João de Albuquerque de Melo Pereira e Cáceres'.

Boca da Lagoa Uberava, Arquivo Público de Mato Grosso. Lata 1791.

'Causa das doenças dos índios'.

Lisboa, Museu Bocage, ARF 20, ms.

'Prospecto filosófico da serra de São Vicente e seus estabelecimentos'. Biblioteca Nacional do Rio de Janeiro, ms. 21, 2, 2, n 12.

'Carta a Luís de Albuquerque Melo Pereira e Cáceres'.

Lisboa, Palácio de Queluz, Arquivo Histórico Ultramarino, cód. 613/614.

'Viagens Filosóficas, ou dissertação sobre as importantes regras que o filósofo naturalista, nas suas peregrinações, deve principalmente observar'. Academia das Ciências de Lisboa, ms. 405. Série Vermelha.

Viagem filosófica de Alexandre Rodrigues Ferreira. Ciclo de conferências. Lisboa, Academia de Marinha.

Viagem filosófica pelas capitanias do Grão-Pará, Rio Negro, Mato Grosso e Cuiabá (1783-1793): uma síntese no seu bicentenário. Brasília/Belém, Conselho Nacional de Desenvolvimento Científico e Tecnológico/Museu Emílio Goeldi. 
Correa Filho, Virgílio

1942

Correa Filho, Virgílio 1939

Ferraz, Márcia

Helena Mendes 1997

Ferreira, Alexandre

Duarte Rodrigues s. d.

Ferreira, Alexandre Rodrigues

s. d.

Ferreira, Alexandre Rodrigues 1974

Ferreira, José Joaquim e Almeida Serra, Ricardo Franco 1874

Fontes, Glória Marly Duarte de Carvalho s. d.

Goeldi, Emílio 1982

Hartmann, Thekla 1975

Humboldt, Alejandro de (trad.) 1985

Lima, Américo Pires 1953

Mittermeier, Russel et alii

1992

Nizza da Silva, Maria Beatriz 1999

Rodrigues de Areia, M. L. et alii 1991

Sá, Manuel José Maria da Costa e 1817

Simon, Willian Joel 1983

Tavares da Silva, D. A. maio-jun. $1947 \mathrm{a}$
Luiz de Albuquerque (fronteiriço insigne).

Rio de Janeiro, Imprensa Nacional.

Alexandre Rodrigues Ferreira, vida e obra do grande naturalista brasileiro. São Paulo, Cia. Editora Nacional.

As ciências em Portugal e no Brasil (1777-1822): o texto conflituoso da química. São Paulo, Educ/Fapesp.

'Enfermidades endêmicas da capitania de Mato Grosso'. Em Glória Marly de Carvalho Fontes, Alexandre Rodrigues Ferreira: aspectos de sua vida e obra. Belém, Instituto Nacional de Pesquisa da Amazônia.

Viagem filosófica ao rio Negro. Belém/Brasília, Museu Paraense Emílio Goeldi/ Conselho Nacional de Desenvolvimento Científico e Tecnológico.

Viagem filosófica pelas capitanias do Grão-Pará, Rio Negro, Mato Grosso e Cuiabá. Memórias antropológicas. Brasília, Conselho Federal de Cultura.

'Reflexões sobre a capitania de Mato Grosso'.

Revista do Instituto Histórico e Geográfico Brasileiro, tomo XII, pp. 377-99.

Alexandre Rodrigues Ferreira: aspectos de sua vida e obra.

Belém, Instituto Nacional de Pesquisa da Amazônia.

Alexandre Rodrigues Ferreira.

Brasília, Editora da Universidade de Brasília.

A contribuição da iconografia para o conbecimento de indios brasileiros do século XIX. São Paulo, USP. Coleção Museu Paulista, série Etnologia, vol. 1.

Viajes a las regiones equinocialles del nuevo mundo.

Caracas, Monte Avila Editores, vol. 1.

O doutor Alexandre Rodrigues Ferreira.

Lisboa, Agencia Central de Ultramar.

Viagem philosophica - uma redescoberta da Amazônia - 1972-1992.

Rio de Janeiro, Index.

A cultura luso-brasileira: da reforma da universidade à independência do Brasil. Lisboa, Estampa.

Memória da Amazónia.

Coimbra, Museu Antropológico da Universidade de Coimbra.

'Elogio do doutor Alexandre Rodrigues Ferreira'. Em História e memórias da Academia Real das Sciencias de Lisboa. Lisboa, tomo V, parte $1^{\text {a }}$.

Scientific expeditions in the portuguese overseas territories (1783-1808). Lisboa, Instituto de Investigação Científica Tropical.

'O cientista luso-brasileiro dr. Alexandre Rodrigues Ferreira - notas para o seu estudo'. Boletim da Sociedade de Geografia de Lisboa, pp. 279-357. 
Tavares da Silva, D. A. mar.-abr. 1947b

\section{Fontes iconográficas}

\section{Conselho Federal de Cultura}

1971
'O cientista luso-brasileiro dr. Alexandre Rodrigues Ferreira - notas para o seu estudo'. Boletim da Sociedade de Geografia de Lisboa, pp. 117-88.

Viagem filosófica pelas capitanias do Grão-Pará, Rio Negro, Mato Grosso e Cuiabá. São Paulo/Rio de Janeiro, Monumento/Artes Gráficas Gomes de Souza, vol. I. Geografia e Antropologia.

Desenho de gentios, animais quadrúpedes, aves, amphibios, peixes e insectos da Expedição Philosophica do Pará, Rio Negro, Mato Grosso e Cuyabá. Museu Bocage, ARF, 32, vols. 1 e 2.

Desenhos de gentios, animais quadrúpedes, aves, amphibios e peixes; armas, instrumentos músicos e mechanicos, vestidos, ornatos e utencis domesticos dos mesmos gentios etc. Da Expedição Philosophica do Pará, Rio Negro, Mato Grosso e Cuyabá. Biblioteca Nacional do Rio de Janeiro, códice 21,1,1, A.

Recebido para publicação em outubro de 2000.

Aprovado para publicação em maio de 2001. 